Simulation of Absorption Edge Densitometry

Sin-Tao Hsue

Michael Collins 



\section{DISCLAIMER}

This report was prepared as an account of work sponsored by an agency of the United States Government. Neither the United States Government nor any agency thereof, nor any of their employees, make any warranty, express or implied, or assumes any legal liability or responsibility for the accuracy, completeness, or usefulness of any information, apparatus, product, or process disclosed, or represents that its use would not infringe privately owned rights. Reference herein to any specific commercial product, process, or service by trade name, trademark, manufacturer, or otherwise does not necessarily constitute or imply its endorsement, recommendation, or favoring by the United States Government or any agency thereof. The views and opinions of authors expressed herein do not necessarily state or reflect those of the United States Government or any agency thereof. 


\section{DISCLAIMER}

Portions of this document may be illegible in electronic image products. Images are produced from the best available original document. 


\section{CONTENTS}

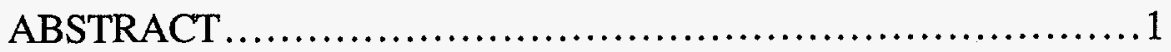

I. INTRODUCTION ...................................... 1

II. SIMULATION METHOD ................................2

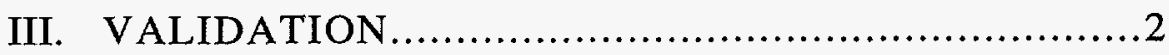

IV. APPLICATION OF THE SIMULATION PROGRAM........9

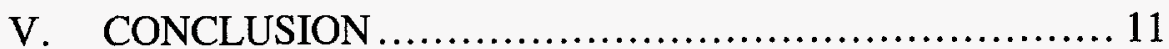

ACKNOWLEDGMENTS $\ldots \ldots \ldots \ldots \ldots \ldots \ldots \ldots \ldots \ldots \ldots \ldots \ldots \ldots \ldots$

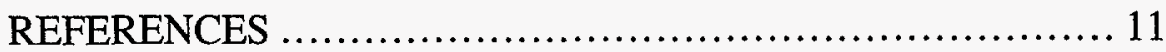




\title{
SIMULATION OF ABSORPTION EDGE DENSITOMETRY
}

\author{
by
}

\author{
Sin-Tao Hsue and Michael Collins
}

\begin{abstract}
A method for simulating absorption edge densitometry has been developed. This program enables one to simulate spectra containing any combination of special nuclear materials (SNM) in solution. The method has been validated with an analysis method using a single special nuclear material in solution or a combination of two types of SNM separated by a Z of 2 . This computer simulation has been used to explore the bias caused by the presence of, for example, plutonium in a determination of uranium concentration. We have also used this program to explore better methods of analyzing densitometry data.
\end{abstract}

\section{INTRODUCTION}

Absorption-edge densitometry has become an important analytical tool for safeguarding reprocessing plants. It has been used successfully to measure the product uranium and plutonium solutions generated from the plutonium recovery plants. ${ }^{1}$ It has also been used, in conjunction with the $\mathrm{x}$-ray fluorescence (XRF) technique, to determine simultaneously the plutonium and uranium concentrations of dissolver solutions: the input solution of plutonium recovery plants. ${ }^{2,3}$

This report describes a method for computer-simulated absorption edge densitometry. The applications of such a technique are severalfold. First, the simulation can be used as a training tool; an operator can input the concentrations of special nuclear materials (SNM) and the attenuated spectrum can be displayed for that solution. Second, simulation can be used as a research tool. Although most of the work should be done by actually preparing the solutions and measuring the solutions with the densitometer, such a process is time consuming, and the preparation of samples is expensive. Because of the time and expense, a limited number of studies have been done, with the majority of the work performed on the dissolver solutions of reprocessing plants. The presence of minor isotopes such as neptunium and americium leads to interference, which may potentially cause bias in the assay results. Simulations can be performed to study the effect of minor isotopes upon densitometry determination. Third, the densitometry technique has the potential of being quite precise for the simultaneous assay of solutions containing a mixture of plutonium and uranium; this has not been explored thoroughly. Simulation can be used to study the different ways of analyzing data. Finally, simulation may also help in deciding the ideal sample thickness for various concentration ranges. 
This is the first portion of a two-part report. Our goal is to simulate spectra from the hybrid densitometer system, namely both the XRF and densitometry processes. Because densitometry is more straightforward than XRF, we decided to simulate the densitometry process first.

The densitometry process is physically simple. A continuous-energy x-ray beam with a specific end point is directed through a solution containing SNM. Some of the beam is absorbed by the atoms in the solution, generating the characteristic $x$-rays of the element. Some of the incident $\mathrm{x}$-rays will undergo Compton scattering. The beam is, therefore, attenuated as it goes through the solution. Finally, some of the beam will emerge from the solution without losing energy; this transmitted beam is measured by the densitometer detector. A narrow collimator, typically $0.75 \mathrm{~mm}$ in diameter, is placed between the detector and the solution, thereby minimizing detection of multiple scattering processes.

\section{SIMULATION METHOD}

There are at least two different ways to simulate the densitometry process. For example, a Monte Carlo particle-transport method could be used to generate a simulated spectrum. However, because we strive for at least $0.01 \%$ or better calculational precision, the required computing time would be prohibitively long.

The other alternative is to start with the reference spectrum. This is the spectrum obtained from the densitometer by using a sample vial that contains only the nominal matrix solution. A sample reference spectrum is shown in Fig. 1. Because this spectrum was taken with the actual densitometer system, all the multiple scattering events are taken into account and measured by the detector. The difference between the sample solution and the reference solution is, therefore, the presence of SNM. To generate the simulated spectrum for the SNM solution, we need to attenuate the net reference spectrum, channel by channel, according to the following equation:

$$
I(E)=I_{0}(E) \cdot \prod_{i=1}^{j} \exp \left(-\mu_{i}(E) \cdot \rho_{i} \cdot x\right)
$$

where $E$ is the energy corresponding to a channel, $i$ is the SNM element index, $j$ is the number of SNM elements in the solution, $\mu_{i}$ is the mass absorption coefficient of element $i$ at energy $E, \rho_{i}$ is the known density of element $i$ in the solution, and $x$ is the thickness of the solution.

Figure 2 shows the simulated spectrum, using this method, for a solution that contains $200 \mathrm{~g} / \ell$ of uranium. The lower curve in Fig. 2 shows the spectrum measured with an actual $208 \mathrm{~g} / \ell$ solution. It is observed that the two curves are quite similar. The only exception is that near the absorption edge, where the simulated spectrum shows a sharp discontinuity, the actual spectrum is more "rounded." This difference is a result of the finite resolution of the detector, which tends to distribute some counts near the edge into neighboring channels. This difference does not affect the analysis because the data near the edge are not used in data analysis.

\section{VALIDATION}

The critical test of this method is that, when analysis is performed upon a simulated spectrum, the calculated SNM content should be identical to the "known" content. For example, if we simulate a spectrum for a solution that contains $200 \mathrm{~g} / \ell$ of uranium $(200 \mathrm{gU} / \ell)$, and this spectrum 


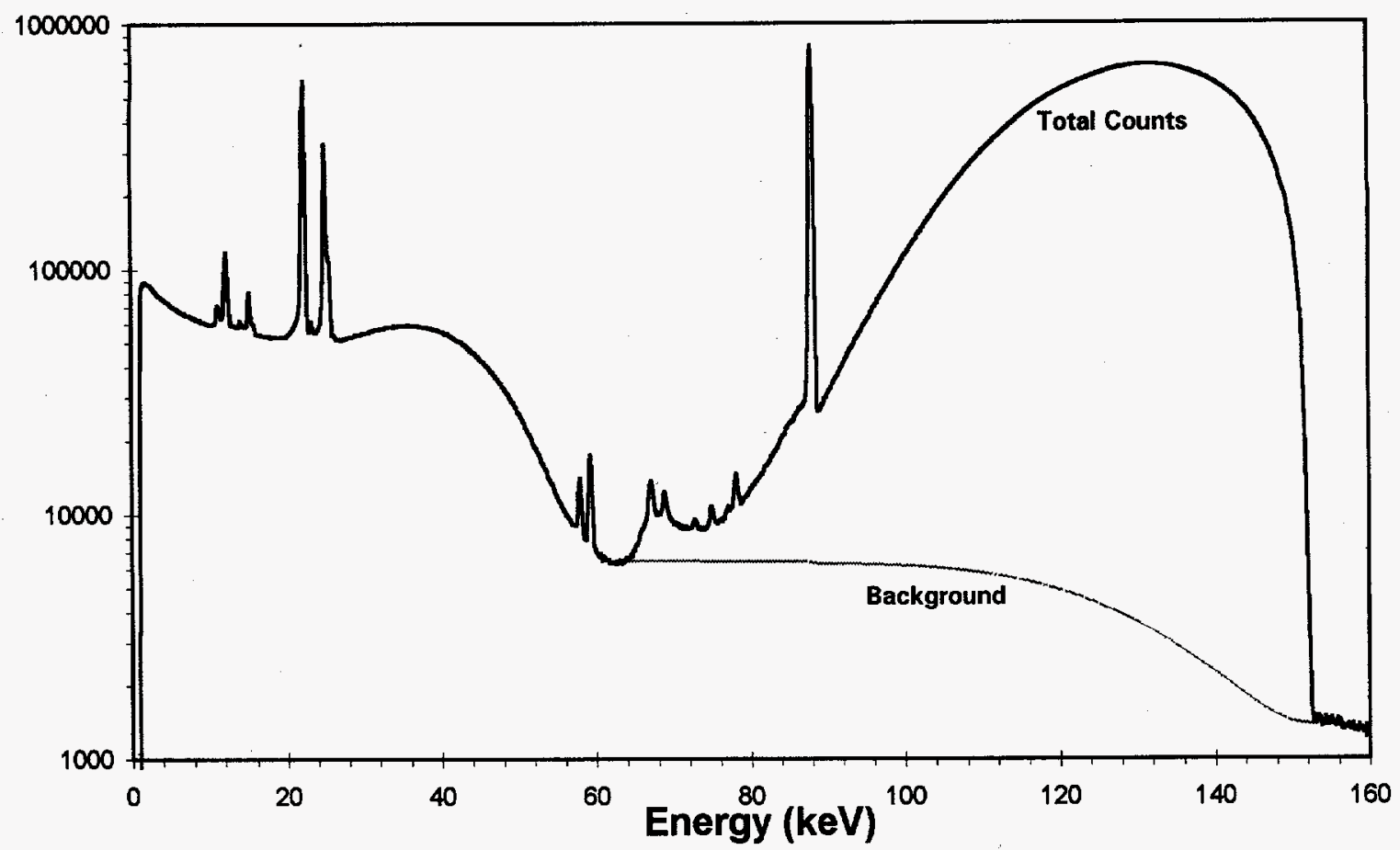

Fig. 1. Reference spectrum of the densitometer taken with the matrix solution, in this case 3 molar $\mathrm{HNO}_{3}$.

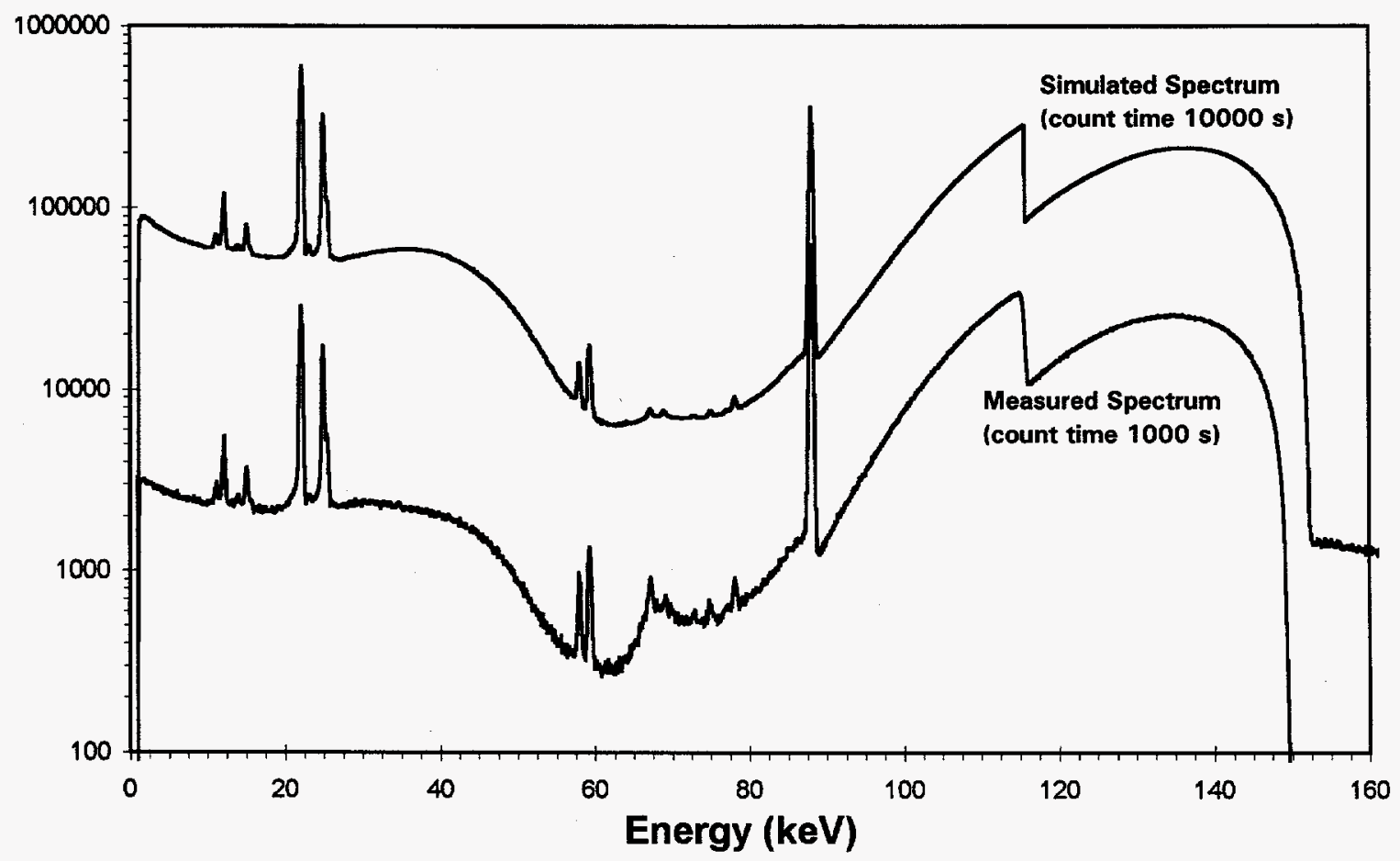

Fig. 2. Simulated uranium spectrum and actual uranium spectrum taken with $x$-ray generator based densitometer. 
is submitted for densitometry analysis, the assay result should indicate $200 \mathrm{gU} / \ell$. In fact, the assay results should be identical to the known contents for arbitrary concentrations of uranium and plutonium.

Table I shows several comparisons of known and calculated uranium concentrations. The calculated concentrations were obtained by performing densitometry analysis upon simulated spectra. As shown in equation (1), the mass absorption coefficient must be determined, for each SNM element present, at the energy of every channel in the simulated region. Because different values of $\mu$ are reported in various cross-section tabulations, it is important that we identify the source of our $\mu$ data. We obtained mass absorption (total minus coherent scattering) cross sections from Storm and Israel. 4 Values of $\mu$ between energies listed in Storm and Israel were obtained via linear interpolation in $\log (\mu)$ versus $\log (E)$ space. A solution thickness of $2 \mathrm{~cm}$ was assumed in all calculations.

In Table I, the first column shows the known uranium concentration used for simulating the assay spectrum. The second column shows the calculated uranium concentration that results from densitometry analysis upon the simulated spectrum. The analysis is based on straight line fitting in $\log \log (1 /$ Transmission) versus $\log$ (Energy) space, where "log" indicates the natural logarithm function. The fitting ranges are those which include approximately $6 \mathrm{keV}$ above and $6 \mathrm{keV}$ below the K-edge as shown in Fig. 3. The fourth column lists the precision from the assay, calculated using the error analysis outlined in Ottmar's report. ${ }^{3}$ Because our reference spectrum was collected for $10000 \mathrm{~s}$, the counting time for each simulated spectrum is also $10000 \mathrm{~s}$. Therefore, each analysis performed on a simulated spectrum must have a precision which corresponds to a $10000 \mathrm{~s}$ counting time. The final column lists the precision after being adjusted to a 1000 -s assay time, multiplying by the square root of 10 . Figure 4 shows a graph of both the ratio and the precision for $1000-\mathrm{s}$ assays.

\begin{tabular}{|c|c|c|c|c|}
\hline \multicolumn{5}{|c|}{ TABLE I. Known Uranium Concentrations and Assayed Values from Simulated } \\
Spectra. \\
\hline \hline $\begin{array}{c}\text { Known U } \\
(\mathrm{g} / \ell)\end{array}$ & $\begin{array}{c}\text { Assayed U } \\
(\mathrm{g} / \ell)\end{array}$ & $\begin{array}{c}\text { Ratio } \\
\text { (Assayed/Known) }\end{array}$ & $\begin{array}{c}\text { Precision (\%) } \\
10 \text { 000-s assay }\end{array}$ & $\begin{array}{c}\text { Precision(\%) } \\
1000 \text {-s assay }\end{array}$ \\
\hline \hline 1 & 1 & 1.000 & 8.160 & 25.805 \\
5 & 5 & 1.000 & 1.649 & 5.213 \\
10 & 10 & 1.000 & 0.835 & 2.640 \\
30 & 30 & 1.000 & 0.293 & 0.927 \\
50 & 50 & 1.000 & 0.183 & 0.587 \\
75 & 75 & 1.000 & 0.133 & 0.420 \\
100 & 100 & 1.000 & 0.107 & 0.339 \\
150 & 150 & 1.000 & 0.083 & 0.264 \\
200 & 200 & 1.000 & 0.074 & 0.234 \\
250 & 250 & 1.000 & 0.070 & 0.223 \\
300 & 300 & 1.000 & 0.071 & 0.223 \\
350 & 350 & 1.000 & 0.073 & 0.232 \\
400 & 400 & 1.000 & 0.078 & 0.247 \\
450 & 450 & 1.000 & 0.085 & 0.269 \\
500 & 500 & 1.000 & 0.094 & 0.297 \\
\hline
\end{tabular}




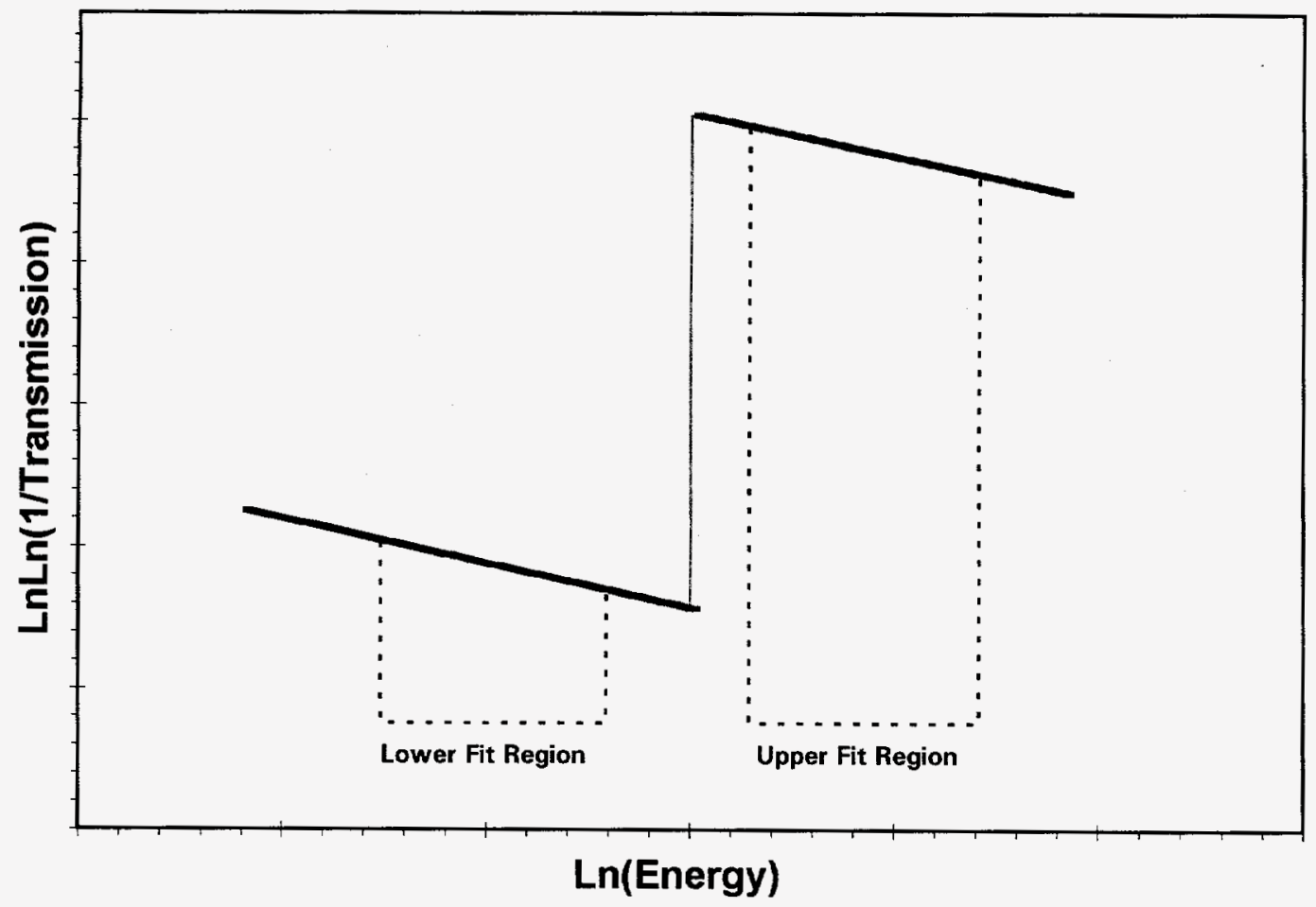

Fig. 3. Regions of data analyzed for a single element densitometer. The fitting region is $6 \mathrm{keV}$ wide above and below the absorption edge.

\section{Uranium Simulation}

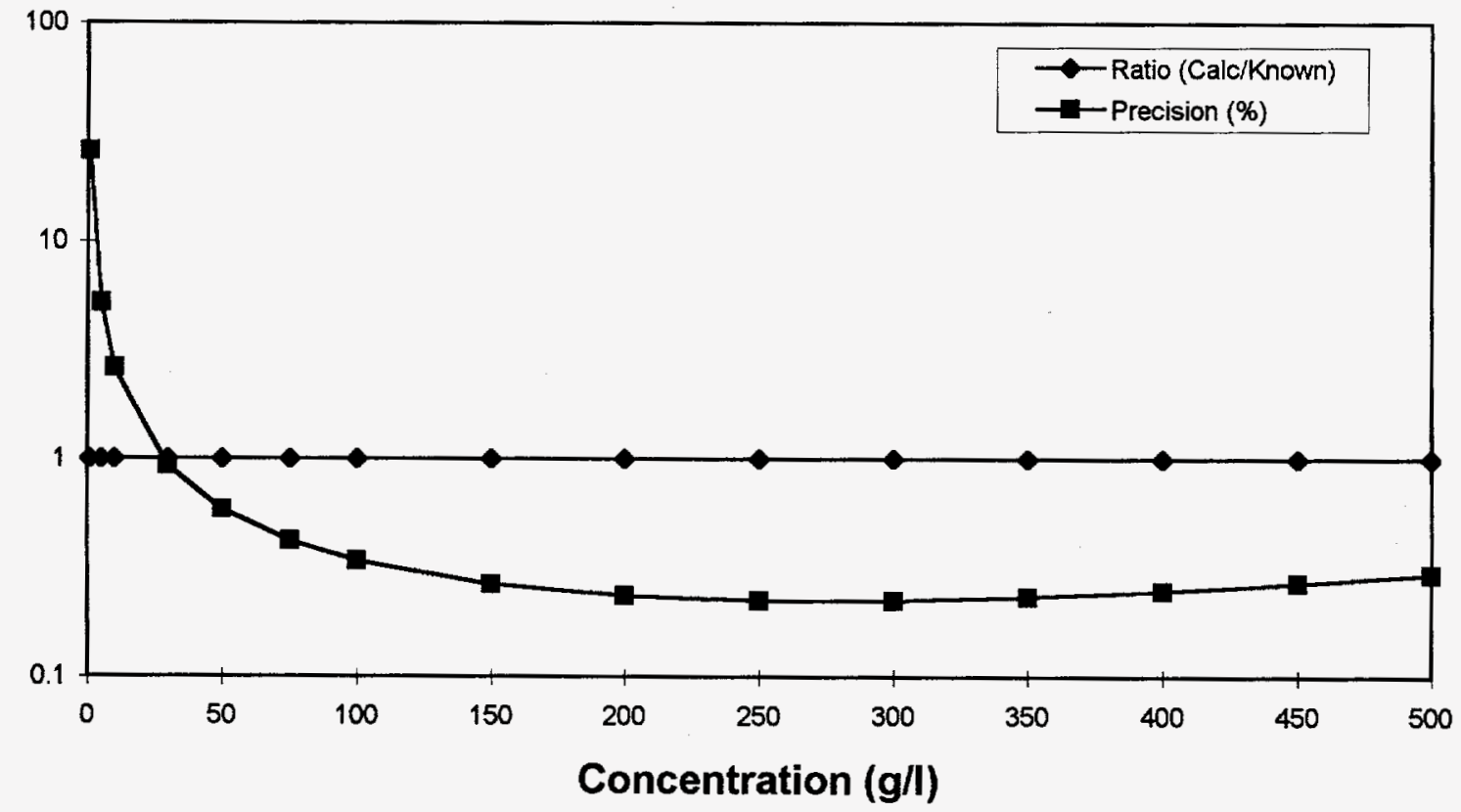

Fig. 4. Analysis of simulated uranium spectrum from $1 \mathrm{~g} / \ell$ to $500 \mathrm{~g} / \ell$. The ratio is that of the analyzed to known concentration. The precision values correspond to an assay time of $1000 \mathrm{~s}$. 
Table I and Fig. 4 show the comparison between the known and the assayed values for uranium; Table II and Fig. 5 show the results of similar trials using plutonium. These tables and figures show that the method does pass the critical test of simulation: namely, the known and assayed SNM concentrations are in perfect agreement. The calculated precision is also quite reasonable, $0.59 \%$ at $50 \mathrm{~g} / \ell$ and $0.23 \%$ at $200 \mathrm{~g} / \ell$ for uranium determination. These values are in good agreement with our actual measurements and also with values reported by Ottmar ${ }^{3}$ and our measurements.

We have also simulated solutions that contain a mixture of plutonium and uranium. We used the analysis method of Ottmar for solving two simultaneous equations to obtain the plutonium and uranium concentrations. We used a solution with a known U/Pu ratio of 2 . The fitting region for the analysis of mixed solution is shown in Fig. 6. Table III summarizes the results. We observed that the ratio of calculated concentration to known concentration was unity for each SNM element. The precision for each concentration is plotted in Fig. 7. These precisions are, again, in good agreement with measurement. In general, the precision in analysis of mixed SNM solutions is worse than that of single-element solutions because, in the mixed case, the interval between the two K-edges is approximately $2 \mathrm{keV}$ in width, whereas in the single element case, the fitting interval is $6 \mathrm{keV}$ in width. As a result, the linear fit includes data from one-third as many channels. The narrow fitting range increases the uncertainty of the end point determination (the $\log -\log (1 / \mathrm{T})$ intercept), which boosts the amount of relative error in the concentration value. For the minor isotope, the precision also degrades as the ratio of $\mathrm{U} / \mathrm{Pu}$ increases; the limit of ratio is around 10. Beyond 10 , the precision of plutonium approaches $20 \%$ or more.

\begin{tabular}{|c|c|c|c|c|}
\hline TABLE II. & $\begin{array}{l}\text { Known Plutonium Concentrations and Assayed Values from Simulated } \\
\text { Spectra. }\end{array}$ \\
\hline \hline $\begin{array}{c}\text { Known } \mathrm{Pu} \\
(\mathrm{g} / \ell)\end{array}$ & $\begin{array}{c}\text { Assayed } \mathrm{Pu} \\
(\mathrm{g} / \ell)\end{array}$ & $\begin{array}{c}\text { Ratio Pu } \\
(\mathrm{A} / \mathrm{K})\end{array}$ & $\begin{array}{c}\text { Precision (\%) } \\
10 \text { 000-s assay }\end{array}$ & $\begin{array}{c}\text { Precision(\%) } \\
1000-\mathrm{s} \text { assay }\end{array}$ \\
\hline \hline 1 & 1 & 1.000 & 7.614 & 24.077 \\
5 & 5 & 1.000 & 1.538 & 4.863 \\
10 & 10 & 1.000 & 0.778 & 2.461 \\
30 & 30 & 1.000 & 0.273 & 0.863 \\
50 & 50 & 1.000 & 0.172 & 0.545 \\
75 & 75 & 1.000 & 0.123 & 0.388 \\
100 & 100 & 1.000 & 0.099 & 0.312 \\
150 & 150 & 1.000 & 0.076 & 0.241 \\
200 & 200 & 1.000 & 0.067 & 0.211 \\
250 & 250 & 1.000 & 0.063 & 0.199 \\
300 & 300 & 1.000 & 0.062 & 0.197 \\
350 & 350 & 1.000 & 0.064 & 0.201 \\
400 & 400 & 1.000 & 0.067 & 0.211 \\
450 & 450 & 1.000 & 0.071 & 0.226 \\
500 & 500 & 1.000 & 0.078 & 0.246 \\
\hline
\end{tabular}




\section{Plutonium Simulation}

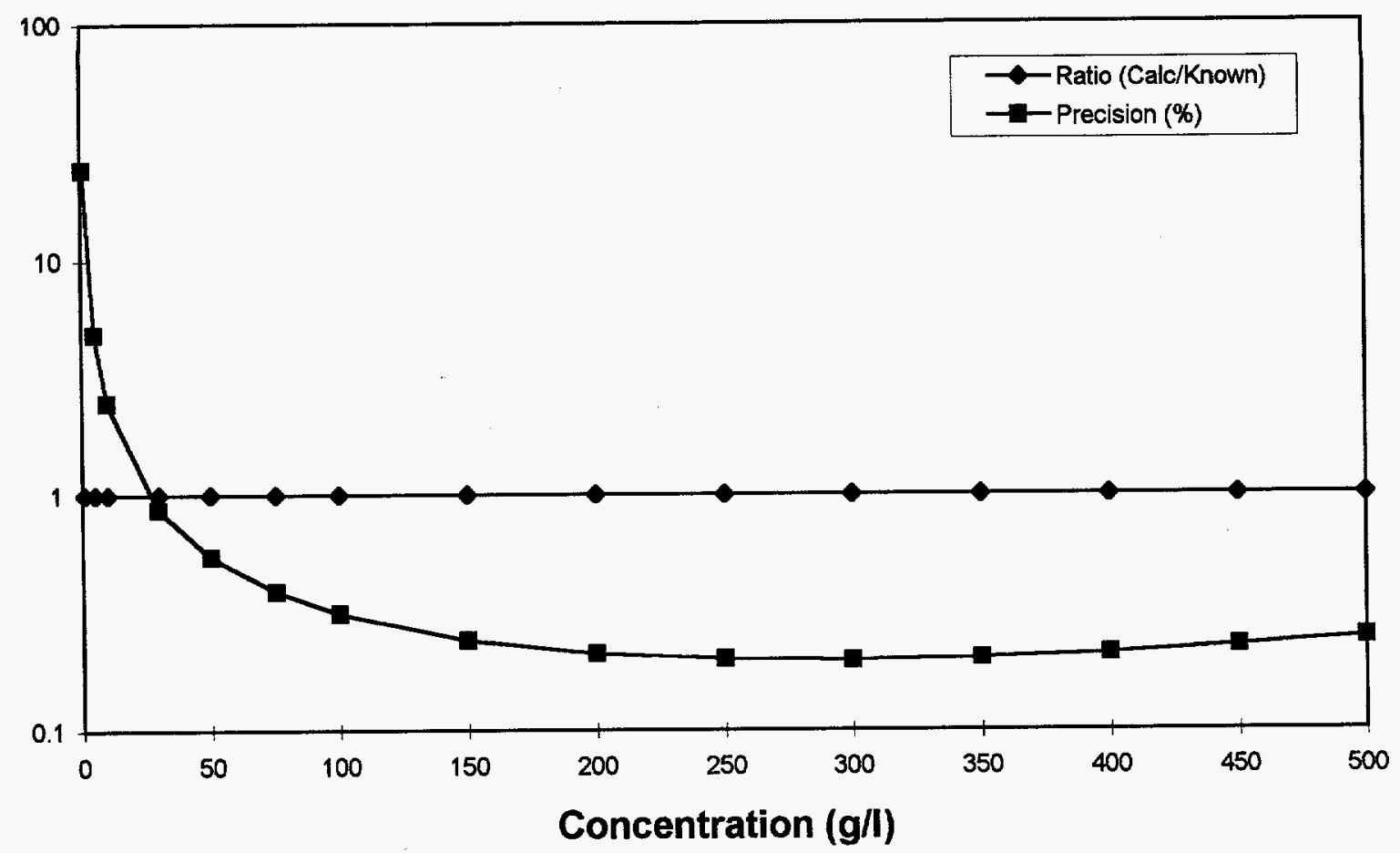

Fig. 5. Analysis of simulated plutonium spectrum from $1 \mathrm{~g} / \ell$ to $500 \mathrm{~g} / \ell$. The ratio is that of the analyzed to known concentration. The precision values correspond to an assay time of $1000 \mathrm{~s}$.

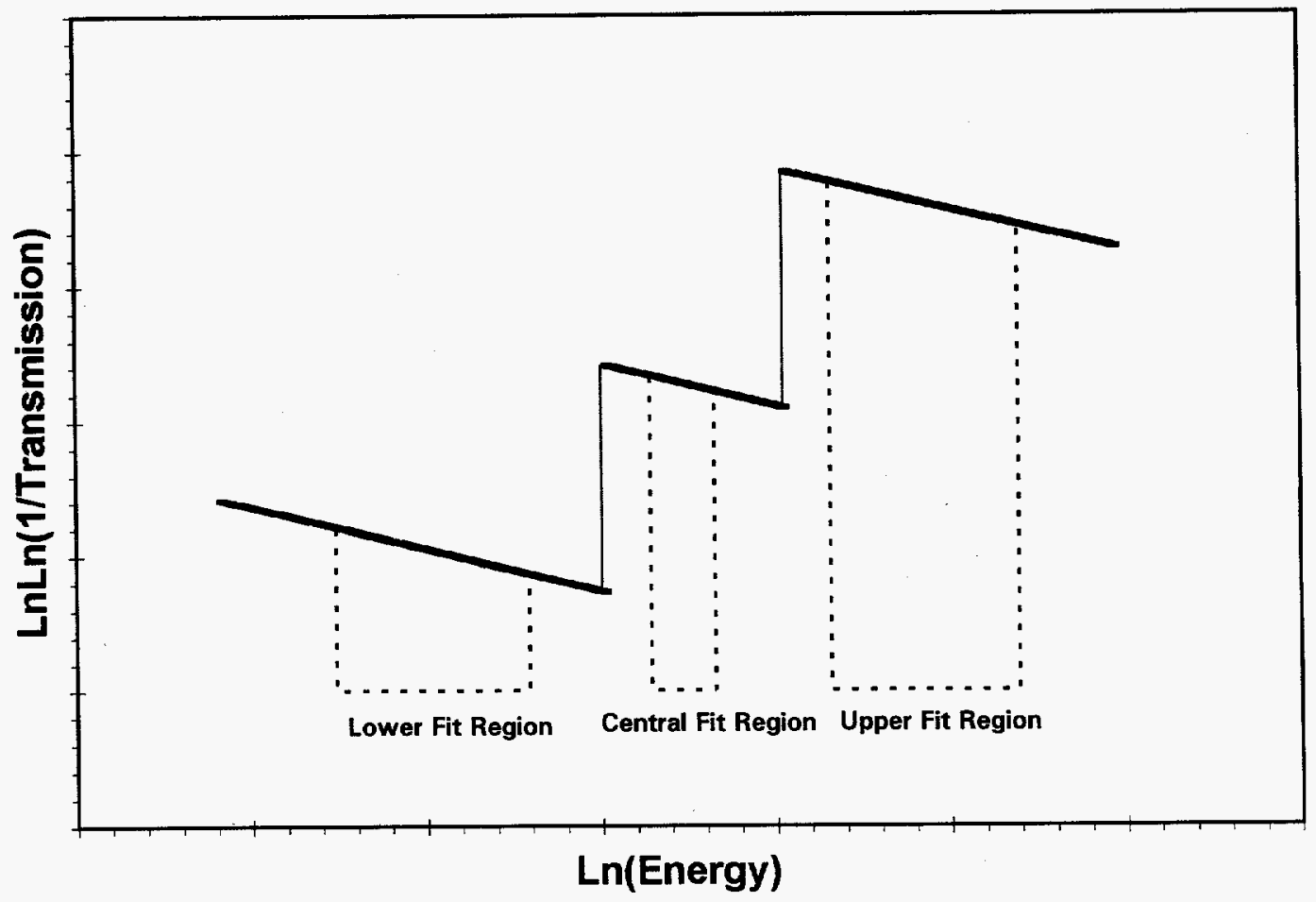

Fig. 6. Regions of data analyzed for a dual element $(\Delta Z=2)$ densitometer. The fitting regions below and above the edges are $6 \mathrm{keV}$ wide; the region in between the edges is $2 \mathrm{keV}$ wide. 


\begin{tabular}{|c|c|c|c|c|c|}
\hline \multicolumn{6}{|c|}{$\begin{array}{c}\text { TABLE III. } \\
\text { Known Uranium and Plutonium Concentrations and Assayed Values } \\
\text { from Simulated Spectra. }\end{array}$} \\
\hline \hline $\begin{array}{c}\text { Known U } \\
(\mathrm{g} / \ell)\end{array}$ & $\begin{array}{c}\text { Known Pu } \\
(\mathrm{g} / \ell)\end{array}$ & $\begin{array}{c}\text { Ratio U } \\
(\mathrm{A} / \mathrm{K})\end{array}$ & $\begin{array}{c}\text { Ratio Pu } \\
(\mathrm{A} / \mathrm{K})\end{array}$ & $\begin{array}{c}\text { Precision U(\%) } \\
10 \text { 000-s assay }\end{array}$ & $\begin{array}{c}\text { Precision Pu(\%) } \\
1000 \text {-s assay }\end{array}$ \\
\hline \hline 2 & 1 & 1.000 & 1.000 & 17.755 & 35.063 \\
10 & 5 & 1.000 & 1.000 & 3.669 & 7.306 \\
20 & 10 & 1.000 & 1.000 & 1.911 & 3.845 \\
60 & 30 & 1.000 & 1.000 & 0.754 & 1.574 \\
100 & 50 & 1.000 & 1.000 & 0.538 & 1.161 \\
150 & 75 & 1.000 & 1.000 & 0.449 & 1.002 \\
200 & 100 & 1.000 & 1.000 & 0.425 & 0.974 \\
300 & 150 & 1.000 & 1.000 & 0.456 & 1.094 \\
400 & 200 & 1.000 & 1.000 & 0.557 & 1.387 \\
500 & 250 & 1.000 & 1.000 & 0.731 & 1.883 \\
600 & 300 & 1.000 & 1.000 & 1.004 & 2.674 \\
700 & 350 & 1.000 & 1.000 & 1.422 & 3.919 \\
800 & 400 & 1.000 & 1.000 & 2.057 & 5.887 \\
\hline
\end{tabular}

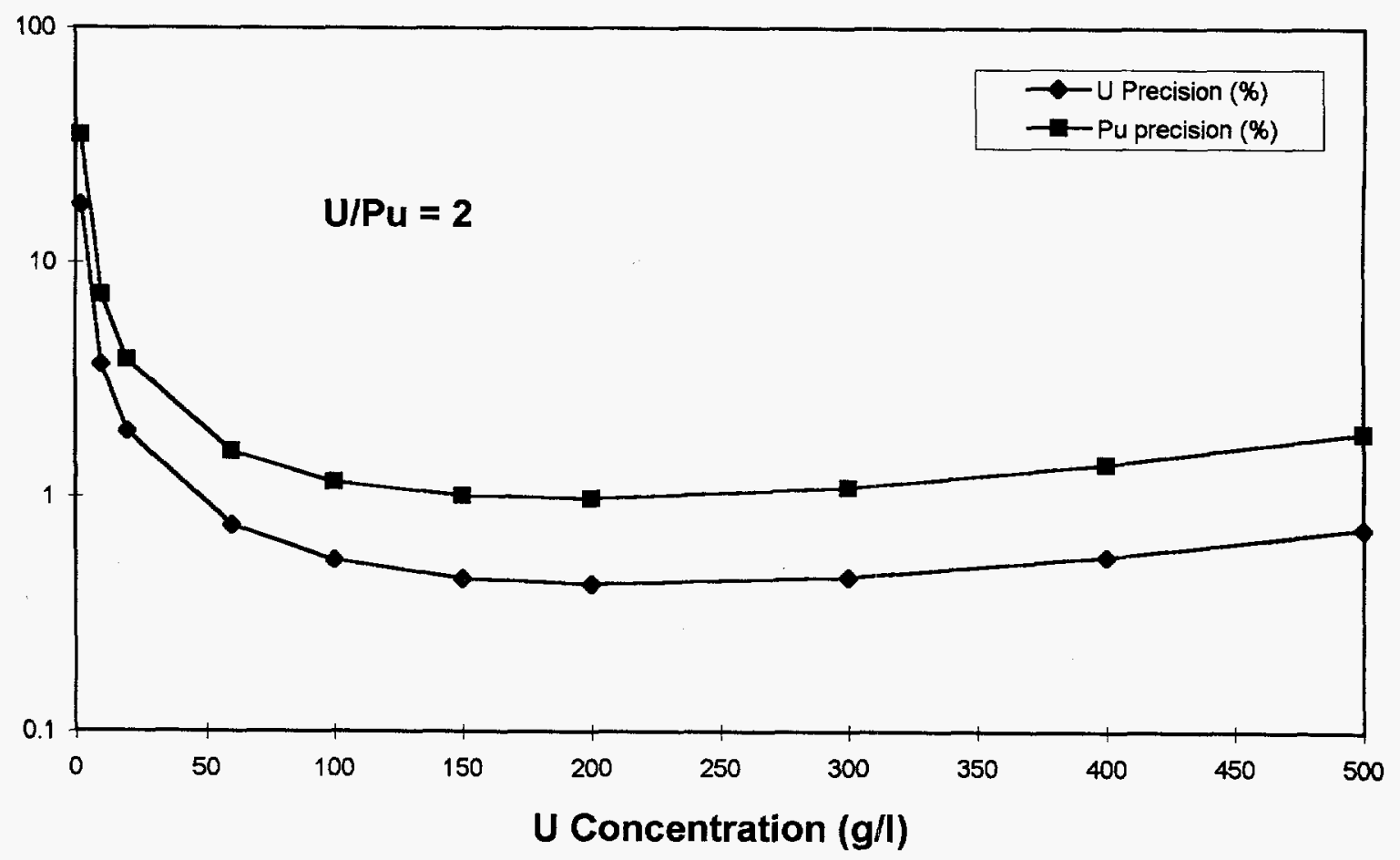

Fig. 7. Precision of a mixture of uranium and plutonium with U/Pu ratio of 2. 


\section{APPLICATION OF THE SIMULATION PROGRAM}

We have developed a computer program that simulates densitometry spectra, which are normally obtained using an x-ray generator. Execution of the program to simulate various concentrations of single and mixed SNM elements has demonstrated that assay results agree with known SNM content. Now the program can be used to explore different possibilities.

Assume we have a solution containing $200 \mathrm{gU} / \ell$; the solution also has some plutonium. If the analyst ignores the plutonium content and analyzes the solution as a pure uranium sample, the assay will be biased; we would like to know the amount of that bias. The results are shown in Table IV and Fig. 8. It shows that there is a bias even when the plutonium is at $0.5 \%$ of the uranium; the bias increases almost proportionally to the concentration of plutonium because the 6-keV fitting region above the uranium K-edge (117.26-124.060 keV) includes the K-edge of plutonium, which has an energy of $121.8 \mathrm{keV}$.

To minimize the bias, we can reduce the fitting region to $(117.26-119.440 \mathrm{keV})$ to avoid the plutonium K-edge. The results are shown in Table V below. We found that the bias is greatly reduced; at $10 \mathrm{gPu} / \ell$ ( $5 \%$ of the uranium concentration), the bias is reduced from $2 \%$ to $0.2 \%$. At the same time, the precision increases from $0.24 \%$ to $0.38 \%$. The worsened precision is due to the narrower fitting region; fewer data points are now used in the linear fit.

The remaining bias can be corrected by the bias correction: ${ }^{3}$

$$
\operatorname{Bias}\left(\mathrm{g} / \mathrm{cm}^{3}\right)=1 / \Delta \mu_{A} * \Sigma_{i} \Delta \mu_{i} * \rho_{i}
$$

For plutonium and uranium, the $\Delta \mu_{\mathrm{Pu}} / \Delta \mu_{\mathrm{U}}=0.0331$. Therefore at $10 \mathrm{gPu} / \ell$, the assayed value of uranium is $199.67 \mathrm{~g} / \ell$. The bias correction is $0.0331 \times 10$ or $0.331 \mathrm{~g} / \ell$. Therefore the final assayed value of uranium is $200.001 \mathrm{~g} / \ell$, which shows very little bias. The bias correction is valid for plutonium concentrations as high as $100 \mathrm{~g} / \ell$. The only penalty is that the precision is worse, from $0.23 \%$ (wide fitting range) to $0.37 \%$ (narrow fitting range) or more. This means that the counting time needs to be doubled to achieve the same precision.

We see that it is possible to correct for the presence of plutonium by narrowing the fitting region and also applying the bias correction; the penalty is worsened precision. The other related

\begin{tabular}{|c|c|c|c|c|}
\hline TABLE IV. & \multicolumn{3}{c|}{ Known Uranium and Plutonium Concentrations Assayed as Single } \\
Element Uranium.
\end{tabular}




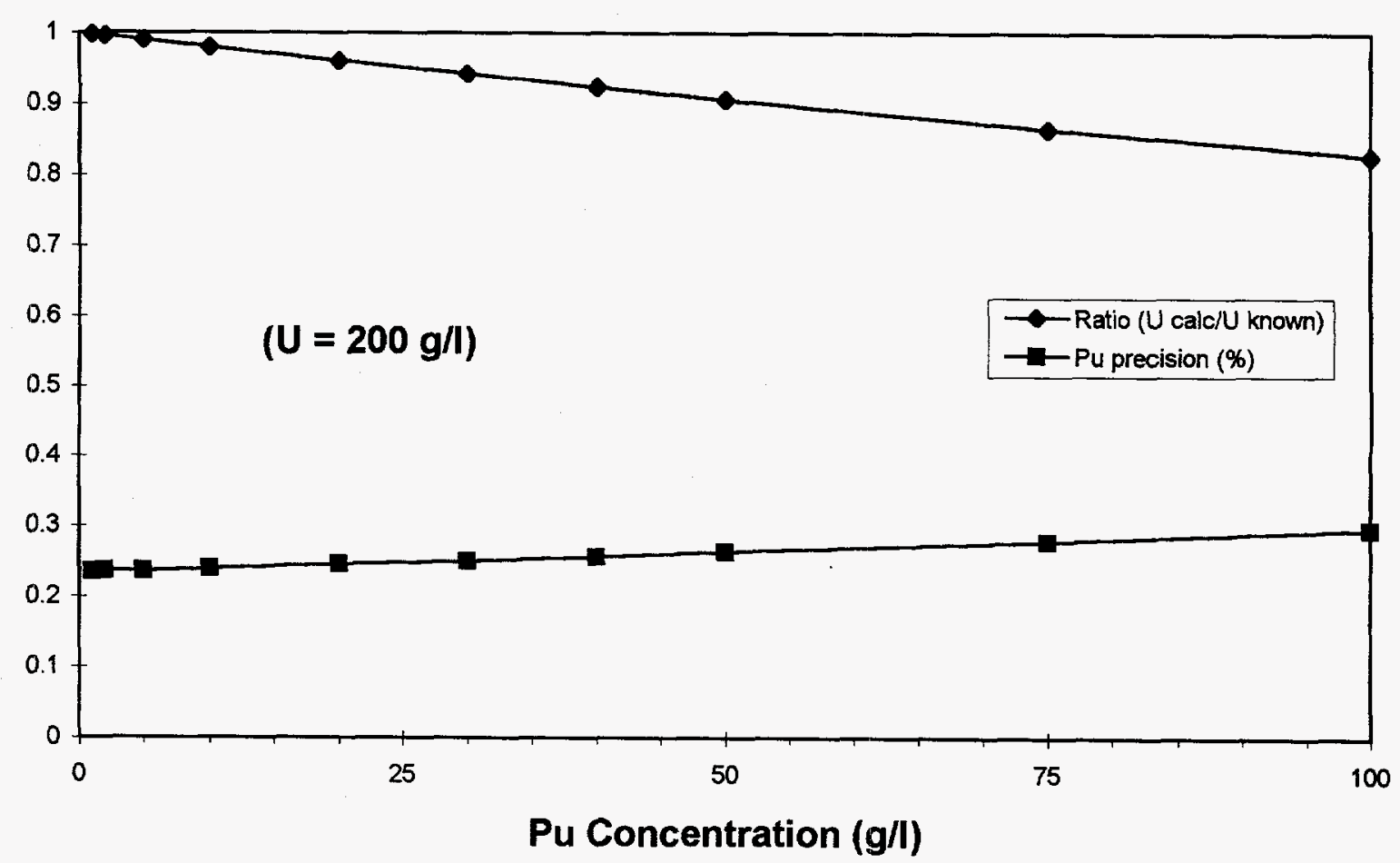

Fig. 8. Bias in the $200 \mathrm{~g} / \mathrm{l}$ uranium concentration determination due to the presence of plutonium in the solution. The spectrum is analyzed as a single element with a wide fitting range.

\begin{tabular}{|c|c|c|c|c|}
\hline TABLE V. & $\begin{array}{l}\text { Known Uranium and Plutonium Concentrations Assayed as Single Element } \\
\text { Uranium. (The higher-energy fitting region has been narrowed to avoid } \\
\text { the plutonium K-edge. }\end{array}$ \\
\hline \hline $\begin{array}{c}\text { Known U } \\
(\mathrm{g} / \ell)\end{array}$ & $\begin{array}{c}\text { Known Pu } \\
(\mathrm{g} / \ell)\end{array}$ & $\begin{array}{c}\text { Assayed U } \\
(\mathrm{g} / \ell)\end{array}$ & $\begin{array}{c}\text { Ratio } \\
\text { (Assayed/Known) }\end{array}$ & $\begin{array}{c}\text { Precision(\%) } \\
1000 \text {-s assay }\end{array}$ \\
\hline \hline 200 & 1 & 199.97 & 1.000 & 0.375 \\
200 & 2 & 199.93 & 1.000 & 0.376 \\
200 & 5 & 199.83 & 0.999 & 0.377 \\
200 & 10 & 199.67 & 0.998 & 0.380 \\
200 & 20 & 199.34 & 0.997 & 0.385 \\
200 & 30 & 199.01 & 0.995 & 0.390 \\
200 & 40 & 198.68 & 0.993 & 0.396 \\
200 & 50 & 198.34 & 0.992 & 0.401 \\
200 & 75 & 197.52 & 0.988 & 0.415 \\
200 & 100 & 196.69 & 0.983 & 0.430 \\
\hline
\end{tabular}

problem is that when the fitting region is changed, the calibration factor, in this case the $\Delta \mu$ value, also changes and needs to be reevaluated.

There is another method for analyzing the data. Assume we know the ratio of $\mathrm{Pu} / \mathrm{U}$ from another means (say, the XRF measurement). Instead of fitting a narrow data range, we will correct the spectrum for the presence of the minor isotope, in this case plutonium. From the known concentration of plutonium (which is also required for the bias correction), we can remove the attenuation due to plutonium for every channel in the fitting range The results of this approach are shown in Table VI. The results show that the bias has been removed by this technique. In 


\begin{tabular}{|c|c|c|c|}
\hline TABLE VI. Known Uranium and Plutonium Concentrations Assayed as Single Element \\
Uranium. (The data in the fitting region have been corrected for the \\
attenuation of the plutonium. The fitting region is the same as for the single \\
element uranium.)
\end{tabular}

addition, the precision of the uranium determination is improved from $0.37 \%$ to $0.23 \%$ because the fitting regions above and below the edge are $6 \mathrm{keV}$ wide. In this example, because the uranium fitting regions were used to determine the uranium concentration, uranium was the "key" element. Because the plutonium concentration was determined from the uranium concentration (using the known Pu/U ratio), plutonium was a "secondary" element.

This method of analyzing data has a further advantage: it can also be applied to the cases in which the proton number $Z$ of the secondary element differs by one from that of the key element $(\Delta \mathrm{Z}=1)$. Two examples of this case are the elements neptunium and americium, with plutonium as the key element. In each case the difference of the two K-absorption edges is only about $3 \mathrm{keV}$, leaving no region for fitting between the elements' edges. This method has the added advantage in that the same calibration constants $(\Delta \mu)$ for single elements can also be used for mixed solutions.

\section{CONCLUSION}

This report summarizes our approach to generating simulated $\mathrm{K}$-absorption edge densitometer spectra. The simulation program has provided densitometry spectra from known concentrations of SNM, which closely resemble actual spectra obtained in the laboratory. The program also serves as a cost-effective tool for the investigation of different analysis techniques, providing simulated spectra for user-defined SNM solutions without the need to prepare actual samples.

\section{ACKNOWLEDGMENTS}

The authors would like to thank J. Sprinkle, Jr., for the many discussions on this subject. We would also like to thank NMT Division for their support on this project.

\section{REFERENCES}

1. H. Ottmar, H. Eberle, N. Doubek, W. Raab, and J. Parus, "Analysis of Th-U, U-Pu and Pu Solutions with a Hybrid K-Edge/ XRF Analyzer," Proceedings of the 13th ESARDA 
Symposium on Safeguards and Nucl. Mater. Manage. (ESARDA, Ispra, Italy, 1991), Vol. 24, pp. 149-157.

2. H. Ottmar, H. Eberle, R. M. Schott, J. Salaun, P. Grison, M. Ougier, H. G. Wagner, J. Goerten, G. Ballette, and P. Louis, "The Use of the Hybrid K-edge Densitometer for the Routine Analysis of Safeguards Verification Samples of Reprocessing Input Liquor," Proceedings of the 13th ESARDA Symposium on Safeguards and Nucl. Mater. Manage. (ESARDA, Ispra, Italy, 1991), Vol. 24, pp. 337 - 344.

3. H. Ottmar, H. Eberle, "The Hybrid K-Edge/ K-XRF Densitometer: Principles - Design Performance," Kernforschungszentrum Karlsruhe report KfK 4590 (February 1991).

4. E. Storm and H. I. Israel, Nuclear Data Tables A7 (1970) pp. 565-681. 